\title{
IBM PENCEGAHAN PENYAKIT DIABETES MELITUS DI KELURAHAN TAMARUNANG KEC SOMBAOPU KABUPATEN GOWA SULAWESI SELATAN
}

\author{
Lismayana Hansur ${ }^{1}$, Dara Ugi ${ }^{1}$, Ami Febriza') \\ 1)Prodi Pendidikan Kedokteran, Fakultas Kedokteran, Universitas Muhammadiyah Makassar, Makasar, Indonesia \\ Corresponding author : Lismayana Hansur \\ E-mail : nadiyahhansur@gmail.com
}

Diterima 03 Agustus 2020, Direvisi 22 September 2020, Disetujui 23 September 2020

\begin{abstract}
ABSTRAK
Diabetes mellitus merupakan salah satu penyakit tidak menular yang memiliki prevalensi yang semakin meningkat di negara berkembang. Rendahnya pengetahuan masyarakat menjadi salah satu penyebab peningkatan tersebut, terutama didaerah pedesaan dan daerah pinggiran kota. Saat ini upaya penanggulangan penyakit diabetes mellitus belum menempati skala prioritas utama dalam pelayanan kesehatan, walaupun diketahui dampak negatif yang ditimbulkannnya cukup besar antara lain komplikasi kronik pada penyakit jantung, hipertensi, sistem saraf, hati, mata, dan ginjal. Mengingat insidensi diabetes mellitus yang terus meningkat dan bahaya komplikasi yang ditimbulkan, maka perlu dilakukan penyuluhan pencegahan dan penanganan penyakit diabetes mellitus termasuk pemeriksaan kadar gula darah agar warga di kelurahan tamarunang kecamatan somba opu kabupaten gowa melakukan pencegahan sejak dini. Metode pengabdian yang telah dilaksanakan meliputi Penyuluhan pencegahan dan terapi diabetes mellitus melalui metode presentasi dan pemeriksaan kadar gula darah menggunakan kit.Hasil kegiatan penyuluhan dan pemeriksaan darah inidapat member informasi dan pengetahuan mengenai pencegahan dan penanganan penyakit diabetes melalui pengaturan pola makan. Selain itu Bagi masyarakat yang belum pernah melakukan pemeriksaan kesehatan sebelumnya, pemeriksaan kesehatan tersebut dapat berfungsi sebagai skrining kesehatan untuk mengetahui status kesehatannya saat ini sehingga dapat diambil tindakan lebih lanjut. Kegiatan penyuluhan berlangsung dengan lancar dan masyarakat mendengarkan dengan antusias, Dari 27 orang yang diperiksa kadar gula darahnya ditemukan 4 orang dengan kadar gula darah melebihi batas normal $(<200 \mathrm{mg} / \mathrm{dl})$.
\end{abstract}

Kata kunci: diabetes mellitus; kadar gula darah; penyuluhan; komplikasi kronik.

\begin{abstract}
Diabetes mellitus, which is one of the non-communicable diseases, has an increasing prevalence in developing countries. Low community knowledge is a factor of this increase, especially in rural and suburban areas. Currently, diabetes mellitus prevention efforts have not been put as the priority in health services. However, it has been understood that the negative impacts are rather severe (e.g., chronic complications in heart disease, hypertension, nervous system, liver, eyes, and kidney). Given the incidence of diabetes mellitus and the danger of its complications, which are increasing, its prevention, including blood glucose examination, need to be socialized so that residents in sub-district Tamarunang, Somba Opu, Gowa can do it early. Some services which have been implemented include socialization of the diabetes mellitus prevention and therapy, through presentation and Test blood glucose with a blood glucose meter. This counseling and blood examination results can provide information and knowledge on how to prevent and manage diabetes through dietary regulation. Besides, this health examination may serve as a health screening for people who have never had a previous medical test to determine their current health status to take further action. The counseling activities went smoothly, and the community listened enthusiastically. Four out of the 27 people who checked their blood sugar levels exceeded normal limits $(<200 \mathrm{mg} / \mathrm{dl})$.
\end{abstract}

Keywords: diabetes mellitus; blood sugar level; counseling; chronic complication.

\section{PENDAHULUAN}

Diabetes Mellitus merupakan salah satu penyakit tidak menular yang menjadi perhatian pada saat ini penyebabkan kematian di negara berpenghasilan rendah dan menengah,pada tahun 2030, 8 dari 10 penyebab utama kematian diprediksi disebabkan penyakit tersebut (Alwan \& MacLean, 2009). Hal ini disebabkan karena prevalensi yang semakin meningkat di negara berkembang. Rendahnya pengetahuan masyarakat menjadi salah satu penyebab peningkatan tersebut, terutama 
didaerah pedesaan. Pemeriksaan Kadar Gula Darah bagi penderita DM sangat penting karena dapat membantu mencegah sehingga mengurangi risiko komplikasi yang berat dan membantu penderita menyesuaikan atau mengatur pola makanan, aktivitas fisik.

Riskesdas 2018 menampilkan data prevalensi diabetes melitus berdasarkan diagnosis dokter yaitu laki-laki sebanyak 1.2\% dan perempuan sebanyak $1.8 \%$. Dipedesaan angka kejadian $1.0 \%$ dan angka kejadian diperkotaan 1.9 diseluruh indonesia. Terjadi peningkatan yaitu tahun 2013 sebanyak 2\%, sedangkan pada tahun 2018 mengalami kenaikan menjadi 3.4\% (Riskesdas, 2018). Meskipun terjadi peningkatan proporsi penderita diabetes mellitus yang terdiagnosis namun proporsi yang tidak terdiagnosis sebelumnya masih besar.

Telah terjadi transisi epidemiologi pola penyebab kematian selama 15 tahun di mana proporsi kematian karena penyakit menular telah menurun sedangkan penyebab kematian karena penyakit tidak menular meningkat(McKeown, 2009). Tahun 2019 penyebab kematian akibat penyakit diabetes di Indonesia mencapai 6\%, angka Prevalensi Diabetes Melitus pada penduduk umur $\geq 15$ tahun meningkat dari $6,9 \%$ menjadi 10,9\%(Direktorat Jenderal Pencegahan dan Pengendalian Penyakit, 2019). Hal ini kemungkinan terjadi seiring dengan berubahnya gaya hidup, sosial ekonomi dan meningkatnya umur harapan hidup yang berarti meningkatnya pola risiko timbulnya penyakit degeneratif seperti diabetes mellitus dan lain sebagainya.

Penyebab Kematian di Kabupaten Gowa 2011 tertinggi akibat Strok (13,6\%), kemudian penyakit jantung iskemik $(8,7 \%)$ dan selanjutnya adalah akibat Diabetes Millitus $(4,3 \%)$ (Kristina et al., 2015). Faktor resiko penyebab diabetes erat kaitannya dengan perilaku hidup yang kurang sehat, yaitu obesitas, kurangnya aktivitas fisik, hipertensi, dyslipidemia, diet tidak sehat, dan merokok(InfoDATIN, 2014). Selain itu kurangnya pengetahuan masyarakat terutama di daerah perbatasan kota seperti Kabupaten Gowa mengenai pencegahan dan pengelolaan diabetes mellitus menjadi faktor yang dapat meningkatkan angka kejadian penyakit tersebut. Sehingga sangat penting untuk melakukan penyuluhan pencegahan penyakitpenyakit degenerative diantaranya adalah diabetes mellitus sebagai pengendalian penyakit untuk mengurangi kematian yang disebabkan penyakit tersebut.

Berdasarkan perubahan

pada masyarakat diperkirakan penderita diabetes tipe 2 akan meningkat dengan cepat terutama karena menurunnya aktivitas fisik dan pola makan yang tidak terkontrol, terutama pada daerah pedesaan dan pinggiran kota yang kekurangan informasi mengenai penyebab timbulnya penyakit(Imelda, 2019). Saat ini upaya penanggulangan penyakit diabetes mellitus belum menempati skala prioritas utama dalam pelayanan kesehatan, walaupun diketahui dampak negatif yang ditimbulkannnya cukup besar antara lain komplikasi pada penyakit jantung kronis, hipertensi, sistem saraf, hati, mata, dan ginjal. Mengingat insidensi diabetes mellitus yang terus meningkat dan bahaya komplikasi yang ditimbulkan, maka perlu dilakukan penyuluhan tentang penyakit diabetes mellitus termasuk pemeriksaan kadar gula darah agar warga di wilayah tamarunang gowa dapat melakukan tindakan preventif dengan lebih mudah.

\section{METODE}

Penyuluhan gejala, komplikasi, pencegahan, dan terapi diabetes mellitus melalui metode presentasi(penyampaian materi) dan tanya jawab. Bagi masyarakat yang belum pernah melakukan pemeriksaan kesehatan sebelumnya, pemeriksaan kesehatan tersebut dapat berfungsi sebagai skrining kesehatan untuk mengetahui status kesehatannya saat ini sehingga dapat diambil tindakan pencegahan lebih lanjut. Bagi penderita DM, terkontrolnya status kesehatan dapat mencegah atau minimal memperlambat munculnya komplikasi. Pemeriksaan kesehatan dan pemeriksaan kadar gula darah dengan menggunakan kit digital

\section{HASIL DAN PEMBAHASAN \\ Pemeriksaan Kadar Gula Darah}

Kegiatan pengabdian ini dilakukan pada hari Minggu tanggal 10 Desember 2017 mulai pkl. 07.30 WITA - selesai di mesjid istiqomah, kelurahan tamarunang Kec Sombaopu kabupaten Gowa. Kegiatan pengabdian yang dilakukan berupa pemeriksaan gula darah sewaktu secara gratis dan penyuluhan tentang Diabetes Mellitus pada sekitar 30 orang warga kelurahan tamarunang baik perempuan maupun laki-laki dari rentang usia 25 tahun sampai 70 tahun ( tabel 1). Penyuluhan tentang DM diberikan oleh dr. dara ugi M.Kes yang merupakan salah satu dosen di Universitas Muhammadiyah Makassar (Gambar 2 ). Pemeriksaan gula darah dilakukan oleh dian Amd.Kes staf laboratorium terpadu Fakultas Kedokteran Universitas Muhammadiyah Makassar (Gambar 1). Dari kuota 35 peserta yang telah mendaftar hanya 27 orang yang menghadiri kegiatan. Kegiatan 
pengukuran gula darah sewaktu pada warga kelurahan tamarunang, Kec Sombaopu Kabupaten Gowa telah dilakukan. Sebanyak 27 orang peserta dengan rentang umur 26 tahun sampai 70 tahun, terdapat 4 peserta laki-laki dan 23 orang perempuan (Tabel 1). Pekerjaan dominan peserta yaitu ibu rumah tangga, 3 orang pegawai swasta dan 1 orang pensiunan (Tabel 1). Beberapa peserta memang memiliki riwayat penyakit diabetes, selain itu asam urat

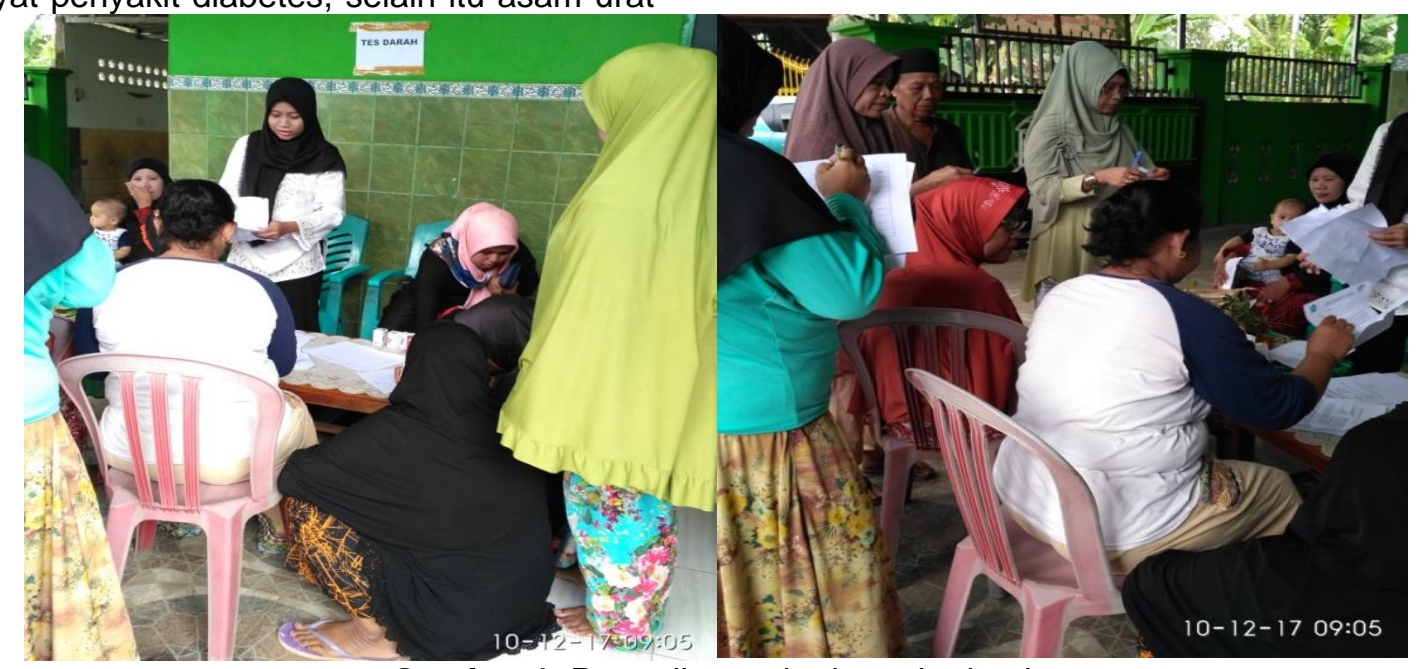

Gambar 1. Pemeriksaan kadar gula darah

Tabel 1. Pemeriksaan Kadar Gula Darah

\begin{tabular}{|c|c|c|c|c|c|c|c|}
\hline No & Nama & $\begin{array}{l}\text { Jenis } \\
\text { Kelamin } \\
(\mathrm{L} / \mathrm{P})\end{array}$ & Usia & Pekerjaan & $\begin{array}{l}\text { Riwayat } \\
\text { penyakit }\end{array}$ & $\begin{array}{l}\text { Hasil } \\
\text { pemerik- } \\
\text { saan }\end{array}$ & $\begin{array}{l}\text { Keterang } \\
\text { an }\end{array}$ \\
\hline 1 & Zubaedah & $P$ & 58 & IRT & Diabetes & 95 & Normal \\
\hline 2 & Rosdiana & $P$ & 37 & IRT & Asam Urat & 82 & Normal \\
\hline 3 & Maryam & $P$ & 40 & IRT & Diabetes & 136 & Normal \\
\hline 4 & Nurmia & $P$ & 41 & IRT & Kolestrol Tinggi & 127 & Normal \\
\hline 5 & Dg. Layu & $\mathrm{P}$ & 47 & IRT & Asam Urat & 141 & Normal \\
\hline 6 & $\begin{array}{l}\text { Jawiyah Dg. } \\
\text { Mami }\end{array}$ & $P$ & 60 & IRT & - & 137 & Normal \\
\hline 7 & Hj. Dg. Rala & L & 73 & Swasta & Komplikasi & 130 & Normal \\
\hline 8 & $\begin{array}{l}\text { Andi } \\
\text { masita }\end{array}$ & $\mathbf{P}$ & 62 & IRT & Diabetes & 276 & Tinggi \\
\hline 9 & Jandi B. & $\mathrm{L}$ & 41 & Swasta & - & 88 & Normal \\
\hline 10 & Fatmawati & $\mathrm{P}$ & 38 & IRT & Rematik & 112 & Normal \\
\hline 11 & $\begin{array}{l}\text { Saharia Dg. } \\
\text { Kanang }\end{array}$ & $\mathbf{P}$ & 49 & IRT & Asam Urat & 289 & Tinggi \\
\hline 12 & Kartina & $\mathbf{P}$ & 48 & IRT & Maag & 224 & Tinggi \\
\hline 13 & Nursanti & $\mathbf{P}$ & 50 & IRT & Asam Urat & 339 & Tinggi \\
\hline 14 & Mausari & $P$ & 52 & IRT & - & 135 & Normal \\
\hline 15 & Baharuddin & $\mathrm{L}$ & 72 & Pensiu-n & - & 88 & Normal \\
\hline 16 & Nuraini & $P$ & 50 & IRT & - & 102 & Normal \\
\hline 17 & Lilis & $P$ & 37 & IRT & Rematik & 127 & Normal \\
\hline 18 & Rosmawati & $\mathrm{P}$ & 47 & IRT & - & 102 & Normal \\
\hline 19 & Normawati & $P$ & 26 & IRT & Rematik & 66 & Normal \\
\hline 20 & Risnawati & $\mathbf{P}$ & 28 & IRT & - & 260 & Tinggi \\
\hline 21 & Ferawati & $P$ & 32 & IRT & Kolestrol Tinggi & 88 & Normal \\
\hline 22 & $\begin{array}{l}\text { St.Aisyah } \\
\text { Dg. Sunggu }\end{array}$ & $P$ & 45 & IRT & Rematik & 92 & Normal \\
\hline 23 & Hamriani & $\mathrm{P}$ & 31 & IRT & Diabetes & 117 & Normal \\
\hline
\end{tabular}




\begin{tabular}{llllllll}
\hline 24 & Kasmawati & P & 38 & IRT & Kolestrol Tinggi & 98 & Normal \\
25 & Sri Lestari & $\mathrm{P}$ & 28 & IRT & Lever,Rematik & 74 & Normal \\
26 & Ansar & L & 34 & Swasta & - & 117 & Normal \\
27 & Dg. Tene & P & 30 & IRT & - & 84 & Normal \\
\hline
\end{tabular}

Dari 27 orang yang diperiksa kadar gula darahnya ditemukan 5 orang dengan kadar gula darah melebihi batas normal ( $<200 \mathrm{mg} / \mathrm{dl}$ ) yaitu : $276 \mathrm{mg} / \mathrm{dl}, 289 \mathrm{mg} / \mathrm{dl}$, dan $224 \mathrm{mg} / \mathrm{dl}, 339 \mathrm{mg} / \mathrm{dl}$ dan $260 \mathrm{mg} / \mathrm{dl}$ (dalam tabel dicetak tebal). Kelima orang tersebut diberikan pengarahan lebih lanjut tentang DM dan bahayanya oleh dr.Dara Ugi.M.Kes, serta diberikan pengarahan khusus untuk menghindari terjadinya komplikasi. Dari kelima orang dengan kadar gula tinggi tersebut 4 orang diantaranya berusia 40 tahun keatas yaitu 48,49,50 dan 62 dan satu diantaranya masih muda yaitu berusia 28 tahun. Semuanya berjenis kelamin perempuan dan didominasi oleh ibu rumah tangga. Dua orang diantaranya memiliki riwayat penyakit diabetes, 2 orang lainnya memiliki riwayat asam urat dan 1 orang penyakit maag.

\section{Penyuluhan Dan Penyampaian Materi Pencegahan dan Penanganan Diabetes}

Setelah Kegiatan pengukuran gula darah sewaktu pada 27 orang warga kelurahan tamarunang, Kec Sombaopu Kabupaten Gowa, Selanjutnya peserta diarahkan untuk mengikuti penyuluhan dan mendengarkan materi mengenai pencegahan dan penanganan diabetes.

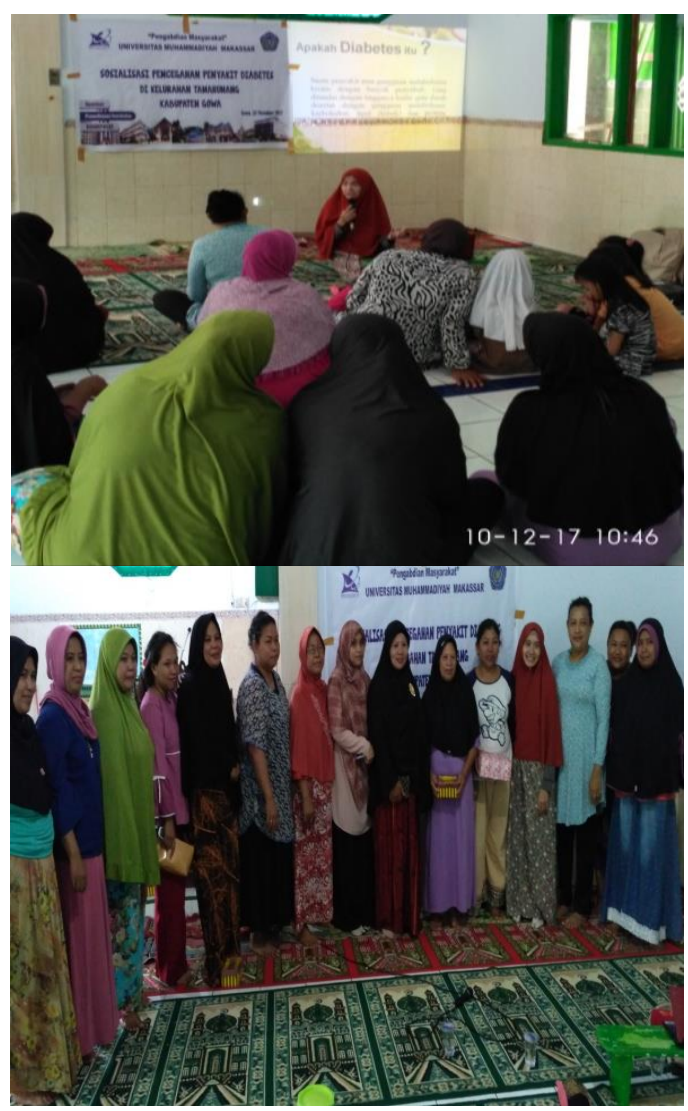

Gambar 2. Sosialisasi dan penyampaian materi pencegahan dan penanganan Penyakit diabetes

Adapun materi yang disampaikan adalah sebagai berikut: Diabetes mellitus atau kencing manis adalah suatu penyakit dimana kadar gula (glukosa) darah dalam keadaan puasa melebihi $110 \mathrm{mg} / \mathrm{dl}$ dan melebihi 200 $\mathrm{mg} / \mathrm{dl}$ dalam keadaan tidak puasa. Gejala umum pasien penderita diabetes adalah sering buang air kecil, cepat lelah dan mengantuk, berat badan menurun drastis, selalu merasa lapar dan gatal-gatal disekitar kemaluan. Komplikasi penyakit diabetes mellitus meliputi kerusakan ginjal, luka yang susah sembuh sampai menyebabkan amputasi, impotensi, penyakit jantung, stroke, kebutaan, gigi tanggal serta hipoglikemia yang dapat menyebabkan pendeirta tidak sadarkan diri.

Pencegahan diabetes dapat dilakukan melalui pola hidup terutama pada penderita diabetes tipe 2(Restyana Noor Fatimah, 2015), pemilihan nutrisi serta pola makan harus sesuai dengan kebutuhan kalori tubuh, jika berlebihan dalam jangka panjang akan menyebabkan penyakit diabetes(Wang et al., 2013). Prevalensi diabetes semakin meningkat disebabkan perubahan pola konsumsi 
masyarakat yang sering menkonsumsi makanan tak sehat seperti makanan cepat saji (fast food) selain itu juga karena kurang aktifitas sehingga olahraga dapat menjadi salah satu jalan pencegahan(Pereira et al., 2005). Pada kegiatan ini juga di sarankan kepada peserta untuk memulai hidup sehat, yaitu diet sehat, olahraga, menghindari stress. Mewaspadai penyakit diabetes jua sempat disampaikan pemateri, sehingga dianjurkan untuk berhati hati karena Penyakit ini menyerang perlahanlahan dan kadang-kadang tidak disadari.

Kurangnya pengetahuan masyarakat terhadap bahaya penyakit diabetes mellitus, dan pengendaliannya menyebabkan penyakit ini semakin banyak terjadi di masyarakat(Bruce et al., 2003). Kegiatan penyuluhan ini diharapkan dapat memutus keterbatasan masyarakat mengenai pengetahuan tentang pencegahan dan penanganan penyakit diabetes. Peserta diharapkan mampu mencegah terjadinya penyakit diabetes, selain itu para penderita dan lingkungan terdekat dapat mengetahui mengenai manajemen terapi diabetes yang tepat, sehingga sedini mungkin dapat mencegah progresivitas penyakit diabetes menjadi penyakit yang parah dengan problem komplikasi seperti neuropati, kebutaan, jantung koroner, hipertensi, dan problem renal.

\section{SIMPULAN DAN SARAN Simpulan}

Kelurahan tamarunang kecamatan sombaopu kabupaten Gowa, adalah daerah pinggiran kota Makassar, masayarakatnya sebagian besar masih sulit mengakses informasi apalagi tentang penyakit diabetes. Mengingat insidensi diabetes yang terus meningkat, maka kegiatan ini sangat tepat dilakukan untuk memberi awareness kepada masyarakat terutama masyarakat kalangan menengah kebawah yang jauh dari akses informasi. Kegiatan penyuluhan berlangsung dengan lancar dam masyarakat mendengarkan dengan antusias, beberapa diantaranya ada yang bertanya tentang DM. Dari 27 orang yang diperiksa kadar gula darahnya ditemukan 5 orang dengan kadar gula darah melebihi batas normal $(<200 \mathrm{mg} / \mathrm{dl})$.

\section{Saran}

Kegiatan pemeriksaan semacam ini hasur dilakukan secara rutin terhadap masyarakat sehingga adanya penyakit DM dapat dideteksi sedini mungkin. Selain itu kegiatan penyuluhan juga sangat bermanfaat untuk meningkatkan pengetahuan masyarakat tentang DM dan komplikasi yang mungkin ditimbulkan sehingga kewaspadaan masyarakat tentang penyakit ini meningkat.

\section{DAFTAR RUJUKAN}

Alwan, A., \& MacLean, D. R. (2009). A review of non-communicable disease in lowand middle-income countries. International Health, 1(1), 3-9. https://doi.org/10.1016/j.inhe.2009.02.0 03

Bruce, D. G., Davis, W. A., Cull, C. A., \& Davis, T. M. E. (2003). Diabetes education and knowledge in patients with type 2 diabetes from the community: The Fremantle Diabetes Study. Journal of Diabetes and Its Complications, 17(2), 82-89.

https://doi.org/https://doi.org/10.1016/S 1056-8727(02)00191-5

Direktorat Jenderal Pencegahan dan Pengendalian Penyakit. (2019). Buku Pedoman Penyakit Tidak Menular.

Imelda, S. I. (2019). Faktor-Faktor Yang Mempengaruhi Terjadinya diabetes Melitus di Puskesmas Harapan Raya Tahun 2018. Scientia Journal, 8(1), 2839.

https://doi.org/10.35141/scj.v8i1.406

InfoDATIN. (2014). Waspada Diabetes. Pusat Data Dan Informasi KemenKes RI, 1-8.

Kristina, K., Pangaribuan, L., Bisara, D., \& Suriani, O. (2015). GAMBARAN PENYEBAB KEMATIAN DI KABUPATEN GOWA PROVINSI SULAWESI SELATAN TAHUN 2011 (Description of Causes of Death in Gowa District South Sulawesi Province in 2011). Buletin Penelitian Sistem Kesehatan, 18(1), 57-64. https://doi.org/10.22435/hsr.v18i1.4271 $.57-64$

McKeown, R. E. (2009). The Epidemiologic Transition: Changing Patterns of Mortality and Population Dynamics. American Journal of Lifestyle Medicine, 3(1 Suppl), https://doi.org/10.1177/155982760933 5350

Pereira, M. A., Kartashov, A. I., Ebbeling, C. B., Van Horn, L., Slattery, M. L., Jacobs, D. R., \& Ludwig, D. S. (2005). Fast-food habits, weight gain, and insulin resistance (the CARDIA study): 15-year prospective analysis. The Lancet, 365(9453), 36-42. https://doi.org/https://doi.org/10.1016/S 0140-6736(04)17663-0

Restyana Noor Fatimah. (2015). Diabetes Melitus Tipe 2. J MAJORITY, 4(5), 93101. 
https://doi.org/10.14499/indonesianjph arm27iss2pp74

Riskesdas, K. (2018). Hasil Utama Riset Kesehata Dasar (RISKESDAS). In Journal of Physics A: Mathematical and Theoretical (Vol. 44, Issue 8). https://doi.org/10.1088/1751-

8113/44/8/085201

Wang, G., Sun, N., Gao, C., Zhu, X., Sun, Y., Li, C. L. C., Shan, H., Pradhan, V. R., Tierney, J. W., Wender, I., Herrick, D. E., Barbier, J., Marecot, P., PARERA, J. M., VERDERONE, R. J., And, C. L. P., TRAFFANO, E. M., Mekhemer, G. A. H., Liu, Q., ... Ganesh, I. (2013). HUBUNGAN POLA MAKAN DENGAN KEJADIAN PENYAKIT DIABETES MELITUS TIPE-2 DI POLI INTERNA BLU.RSUP. PROF. DR. R. D. KANDOU MANADO Sartika. Ejournal Keperawatan, 1(1), 1-6. https://doi.org/10.1179/1743280412Y.0 000000001 